\title{
Comparative Studies of Heat Flow Rate in the Catalytically Activated Two Stroke SI Engine Components over Base Engine by FEA
}

\author{
Dr. K. Kishor \\ Assistant Professor, Mechanical Engineering Department, Chaitanya Bharathi Institute of Technology (CBIT), Gandipet, Hydeabad, India
}

\begin{abstract}
Knowledge on heat flow rate across the piston, liner and cylinder head of an engine is highly essential for a designer for arriving at a reasonable configuration of the piston, liner and cylinder head without sacrificing the strength. Heat flow rate across the piston, liner and cylinder head of CE (Conventional Engine, referred as 'Base Engine') and CCE (Copper Coated Engine, referred as 'Catalytic Coated Engine'/'Catalytically Activated Engine') was determined to study the performance of lubricating oil. The prediction of percentage increase of heat flow with the help of finite element analysis (FEA) using ANSYS software package is important, in these components, which determines the efficient combustion by means of catalytic coating on the surface of piston crown and over the inside surface of cylinder head. These studies are conducted on CE and also on CCE in order to emphasize the advantage of CCE over CE in producing efficient combustion. The heat flux rate was found to be increasing along both axis and radius of piston, liner and cylinder head of CCE over CE.
\end{abstract}

Keywords: Copper coating, base engine, heat flow rate, FEA, ANSYS

\section{Introduction}

The paper is divided into i) Introduction, ii) Materials and Methods, iii) Results and Discussions, iv) Conclusions, Research Findings, Future scope of work followed by References.

Many researchers adopted different theoretical techniques for predicting the heat flux rate not only in the conventional piston but also in CCE piston employing copper coating. However, these researchers concentrated their efforts for predicting the heat flow either for the piston [1], [2], [3] or the cylinder head $[4[,[5,[6]$, but not the assembly of the piston, liner and cylinder head. That too in all these situations, the major bottleneck was on the choice of boundary conditions close to the practical situations, as no reliable data was available for complex situation of piston and liner of the engine. With advanced computer codes like ANSYS and NISA, attempts on the heat flow rate predictions using finite element analysis increased in the recent past. Finite element analysis permits the calculation of the averaged heat flow rates. The prediction of heat flow in these components is important which determines the efficient combustion by means of catalytic coating on the surface of piston crown and over the inside surface of cylinder head.

\section{Materials and Methods}

This section deals with fabrication of catalytically activated engine and description of finite element analysis.

In the catalytically activated engine (CCE), top surface of piston crown and inner surface of cylinder head were coated with a high thermal conductive catalytic material like copper by flame spraying technique.
Plate 1 shows the photographic view of copper coated piston, liner and copper coated cylinder head, while the photographic view of assembly of copper coated piston, liner and copper coated cylinder head of CCE was shown in Plate 2.

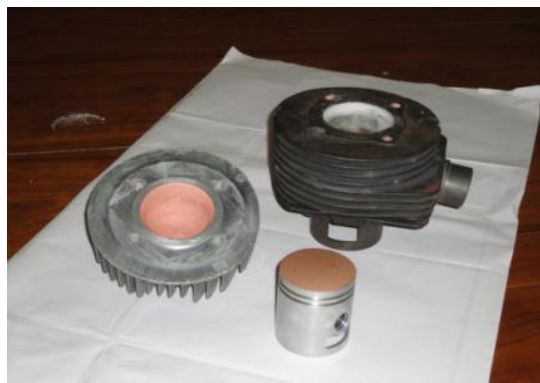

Plate 1 Photographic view of copper coated piston, liner and copper coated cylinder head of $\mathrm{CCE}$

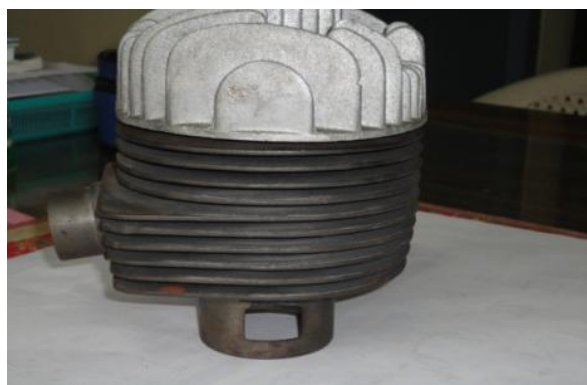

Plate 2 Photographic view of the assembly of CCE

The piston ring grooves, the varying properties of copper coated crown, liner and copper coated cylinder head with differing boundary conditions call for accurate analysis for predicting heat flux rate in the piston, liner and cylinder head. 


\section{International Journal of Science and Research (IJSR) \\ ISSN (Online): 2319-7064}

Index Copernicus Value (2013): 6.14 | Impact Factor (2014): 5.611

\subsection{Assumptions}

The following assumptions are made while analyzing the heat flow in the copper coated piston, liner and cylinder head:

1) The heat transfer between piston and liner is by conduction only.

2) The properties of the various materials used are independent of temperature.

3) Film coefficients are constant and same for all configurations.

4) The average bulk temperatures around the boundaries of components of $\mathrm{CE}$ are constant and same for all the cases of copper coated components of CCE.

5) Air alone exists in the contact area between the liner and the Piston.

Thermal analysis is done employing ANSYS software package to predict the temperature distribution and heat flux rate for different configurations of the piston, liner and cylinder head, in two broad stages as given below:
i. Geometric modeling
ii. Finite element modeling.

In geometric modeling, the outer boundary of one half of the piston, liner and cylinder head are created and necessary patching is generated. Solid quadrant 4-node 55 (axisymmetric) 2-dimensional (acts as plane 55) elements are chosen [7], as their performance is the best and are very cost effective for analysis.

Figure 1 shows the geometric model created for the thermal analysis for CCE (the assembly of copper coated piston, liner and copper coated cylinder head).

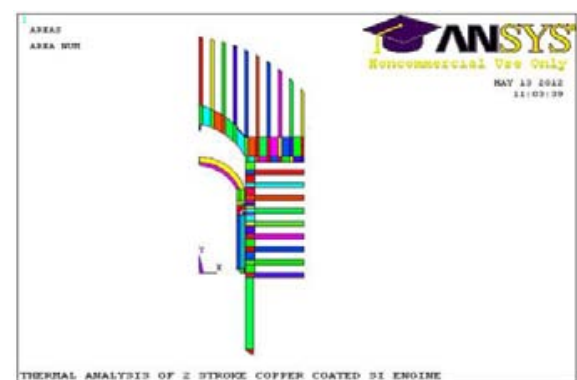

Figure 1: Geometric model created for the thermal analysis for CCE

In the finite element modeling, each patch is further divided into smaller elements in critical areas like crown and cylinder head, where temperature gradients are high while coarser grid is adopted in the regions of the piston and the liner where variation of temperature is not much. Mesh is refined based on convergence requirements and the final mesh is shown in Figure 2 for CCE.

Though the nature of heat transfer is periodic in IC engines, the steady state heat transfer model was assumed with conductive heat transfer phenomena so as to make the system simple and less complicated for determining isotherms and heat flow for copper coated piston, liner and copper coated cylinder head.

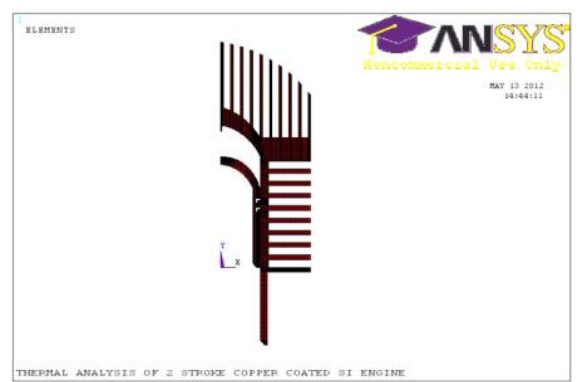

Figure 2 Mesh employed in the thermal analysis for CCE

For determining the heat flow across the SI engine components, the methodology adopted was obtained from the References [3, 6]. Based on literature, the boundary conditions were determined which were close to the practical situation However, the actual boundary conditions for the present problem were obtained with the values of experimentation $[2,8]$ and were given below:

1. Top surface of piston, $\mathrm{h}_{\mathrm{c}}=235 \mathrm{~W} / \mathrm{m}^{2} \mathrm{~K}, \mathrm{~T}=920{ }^{\circ} \mathrm{C}$

2. Bottom side of the piston, $\mathrm{h}_{\mathrm{c}}=450 \mathrm{~W} / \mathrm{m}^{2} \mathrm{~K}$,

$\mathrm{T}=100{ }^{\circ} \mathrm{C}$

3. Air jacket side of liner, $\mathrm{h}_{\mathrm{c}}=200 \mathrm{~W} / \mathrm{m}^{2} \mathrm{~K}, \mathrm{~T}=60{ }^{0} \mathrm{C}$

4. Fins, $\mathrm{h}_{\mathrm{c}}=120 \mathrm{~W} / \mathrm{m}^{2} \mathrm{~K}, \mathrm{~T}=30{ }^{\circ} \mathrm{C}$

In the ANSYS program, nodal temperatures are estimated by evaluating the characteristic matrices. The data has been converted in the post processing into the plotter mode and the plots of heat flow diagrams are obtained for each configuration of the piston, liner and cylinder head.

\section{Results and Discussion}

Figure 3 shows different heat flux regions in the piston, liner and cylinder head of CE, while Figure 4 shows different heat flux regions in the piston, liner and cylinder head of CCE.

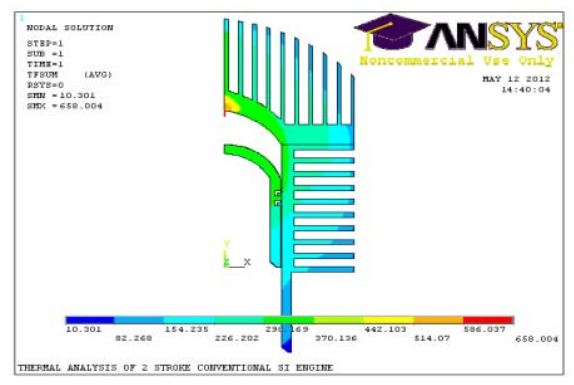

Figure 3 Heat flow in the thermal analysis for CE

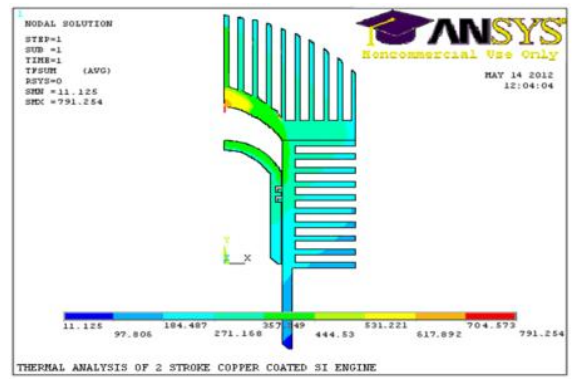

Figure 4 Heat flow in the thermal analysis for $\mathrm{CCE}$

\section{Volume 5 Issue 1 January 2016}




\section{International Journal of Science and Research (IJSR) \\ ISSN (Online): 2319-7064}

Index Copernicus Value (2013): 6.14 | Impact Factor (2014): 5.611

The values of $\%$ increase in the heat flow rate of copper coated engine over conventional engine, predicted by FEM using ANSYS software, at various points (locations) of piston, liner and cylinder head were presented in the Table 1.

Table 1: Data of \% increase in the heat flow rate (predicted by FEA) along the piston, liner and cylinder head of CCE over CE

\begin{tabular}{|c|c|c|}
\hline \multirow{4}{*}{ Component } & Location & $\begin{array}{c}\text { \% deviation in the heat flux } \\
\text { (predicted by FEA) along the } \\
\text { component of CCE over CE }\end{array}$ \\
\hline \multirow{3}{*}{ Piston } & Top surface (Crown) & $20.20 \%$ \\
\cline { 2 - 3 } & Bottom surface & $10.10 \%$ \\
\cline { 2 - 3 } & Outer periphery & $18.20 \%$ \\
\hline \multirow{5}{*}{ Liner } & Inner wall & $15.40 \%$ \\
\cline { 2 - 3 } & Outer radius & $11.90 \%$ \\
\cline { 2 - 3 } & Bottom surface & $7.80 \%$ \\
\hline \multirow{3}{*}{ Cylinder head } & Bottom (inner & $20.20 \%$ \\
\cline { 2 - 3 } & surface) & $14.60 \%$ \\
\cline { 2 - 3 } & Top surface & $18.10 \%$ \\
\hline
\end{tabular}

From the Table 1 it was observed that, the maximum \% increase in the heat flux is more in $\mathrm{CCE}$ over $\mathrm{CE}$ along the axis and along the radius of each component. Since the piston crown and inner surface of cylinder head were copper coated, it absorbs more amount of heat from the surroundings with which temperature increases and hence heat flux also increases. It is desirable to increase the temperature of the surface of the piston and cylinder head by means of copper coating, as the catalytic activity of the copper increases with temperature leading to improve the combustion because copper is a good conductor of heat and hence it promotes combustion stabilization. As the depth of piston and liner and height of cylinder head increases, heat flux decreases. This was due to the thermal resistance offered by the component material against heat flow. As the radius of piston, liner and cylinder head increases, the percentage (\%) increase in the heat flux decreases as their outer periphery was subjected to cooling by means of either lubricating oil or fins or with both.

\section{Conclusions}

1)Along the radius of piston, liner and cylinder head, the heat flux increased by $18-20 \%, 12-15 \%$ and $18-20 \%$ respectively for the catalytically activated engine over that of base engine.

2)In comparison with base engine, the heat flux was higher by $10-20 \%, 8-15 \%$ and $14-20 \%$ respectively along the axis of piston, liner and cylinder head of the copper coated engine.

3) The lubricating oil temperature varied between $106^{\circ} \mathrm{C}$ to $150^{\circ} \mathrm{C}$ for the base engine, while it varied between $127^{\circ} \mathrm{C}$ to $172^{\circ} \mathrm{C}$ for the catalytic coated engine and was within the limits $[9,10]$.

\section{Other Recommendations}

Finite element analysis can be extended to study the thermal analysis (temperature distribution and heat flow rate) across the components of CE and CCE operating on alcohol blended gasoline, thermal stresses and fatigue strength at different operating conditions.

\section{Acknowledgements}

Author thanks the authorities of Chaitanya Bharathi Institute of Technology, Hyderabad for facilities provided. Financial assistance from Andhra Pradesh Council of Science and Technology (APCOST), Hyderabad, is greatly acknowledged. Authors sincerely thank authorities of M/S Sai Surface Coating (P) Limited, Patancheru, Hyderabad, for extending the cooperation in coating the components of the SI engine.

\section{References}

[1] C.H. Li, "Piston Thermal Deformation and Friction Considerations," SAE paper, No. 820086, 1982.

[2] K. Ram Mohan, "Performance of Air Gap Insulated Piston with Diesel," Ph.D. Thesis, Kakatiya University, Warangal, 1995.

[3] V. Esfahanian, A. Javaheri, M. Ghaffarpour, "Thermal Analysis of an SI Engine Piston Using Different Combustion Boundary Condition Treatments," Applied Thermal Engineering, Vol. 26, pp. 277-287, 2006.

[4] Mahdi Hamzehei, Manochehr Rashidi, "Determination of Piston and Cylinder Head Temperature Distribution in a 4-Cylinder Gasoline Engine at Actual Process," In Proceedings of the 4th WSEAS International Conference on Heat Transfer, Thermal Engineering and Environment, pp. 153-158, 2006.

[5] Elisa Carvajal Trujillo, J. Francisco Jiménez-Espadafor José, A. Becerra Villanueva, Miguel Torres García, "Methodology for the Estimation of Cylinder Inner Surface Temperature in an Air-Cooled Engine," Applied Thermal Engineering, Vol. 31, pp.1474 1481, 2011.

[6] Elisa Carvajal Trujillo, J. Francisco Jiménez-Espadafor José, A. Becerra Villanueva, Miguel Torres García, "Methodology for the Estimation of Head Inner Surface Temperature in an Air-Cooled Engine," Applied Thermal Engineering, Vol. 35, pp.202-211, 2012.

[7] Georges Cailletaud, Finite Lement: Matrix Formulation, Ecole des Mines de Paris, Centre des Mat'eriaux, UMR CNRS 7633.

[8] M.V.S. Murali Krishna, "Performance Evaluation of Low Heat Rejection (LHR) Diesel Engine with Alternative Fuels," Ph. D. Thesis, Jawaharlal Nehru Technological University, Hyderabad, 2004.

[9] Ali Jafari, Siamak Kazemzadeh Hannani, "Effect of Fuel and Engine Operational Characteristics on the Heat Loss from Combustion Chamber Surfaces of SI Engines," International Communications in Heat and Mass Transfer, Vol. 33, pp. 122-134, 2006.

[10] J.B. Heywood, Internal Combustion Engine Fundamentals, Thermo-chemistry of fuel air mixtures, Properties of working fluids, McGraw-Hill Book Company, New York, 1988. 


\section{Author Profile}

Dr. K. Kishor received the B.Tech.. degree in Mechanical Engineering, M.Tech. degree in Thermal Engineering and Ph.D. from Jawaharlal Nehru Technological University, Hyderabad in 1987, 2005 and 2014 respectively. Till now, he worked in various capacities in the teaching profession for a total period of 27 years. Since 2004, he is working as Senior Assistant Professor in Mechanical Engineering Department, Chaitanya Bharathi Institute of Technology (CBIT), HYDERABAD. 